\title{
Spatiotemporal characteristics and meteorological determinants of hand, foot and mouth disease in Shaanxi Province, China: a county-level analysis
}

\author{
Li Ding ${ }^{1,2}$, Ning Zhang ${ }^{3,4^{*}}$, Bin Zhu ${ }^{4,5}$, Jinlin Liu ${ }^{4,6}$, Xue Wang ${ }^{4,7}$, Feng Liu ${ }^{8^{*}}$ and Ying Mao M,4 $^{3,4}$
}

\begin{abstract}
Background: Hand, foot and mouth disease (HFMD) is one of the common intestinal infectious diseases worldwide and has caused huge economic and disease burdens in many countries. The average annual incidence rate of HFMD was 11.66\% in Shaanxi during the time span from 2009 to 2018. There are distinct differences within Shaanxi, as it is a special region that crosses three temperature zones. Hence, in this study, a spatiotemporal analysis of Shaanxi was performed to reveal the characteristics of the distribution of HFMD and to explore the meteorological determinants of HFMD.
\end{abstract}

Methods: The county-level and municipal data from Shaanxi Province from 2009 to 2018 were applied to research the spatiotemporal characteristics of HFMD and its meteorological determinants. Time series and spatial autocorrelation analyses were applied to assess the spatiotemporal characteristics of HFMD. This study used spatial econometric panel models to explore the relationship between HFMD and meteorological factors based on the data of 107 counties and 10 municipalities.

Results: The incidence rate of HFMD displayed no variable trend throughout the whole research period. A high incidence rate of HFMD was observed from June to September, corresponding to a time when the climate is characterized by heavy rain, high temperature, and high humidity. The high-incidence areas were mainly located in the central region in Shaanxi, whereas the low-incidence spots were mainly found in Northern Shaanxi. Regarding the meteorological factors analysed in this study, in general, the incidence rate of HFMD in specific regions was positively associated with the rainfall, temperature and humidity.

Conclusion: These results could be applied by the government and the general public to take effective measures to prevent disease. Region-targeted policies could be enacted and implemented in the future according to specific situations in different areas and the relevant meteorological determinants. Additionally, meteorological conditions normally extend to a wide-ranging region; thus, cooperation among surrounding regions is necessary.

\footnotetext{
* Correspondence: ningzhang.xjtu@foxmail.com; sxcdc2020@126.com

${ }^{3}$ School of Public Policy and Administration, Xi'an Jiaotong University, Xi'an, China

${ }^{8}$ Shaanxi Provincial Centre of Disease Control and Prevention, Xi'an, China Full list of author information is available at the end of the article
}

C C The Author(s). 2021 Open Access This article is licensed under a Creative Commons Attribution 4.0 International License, which permits use, sharing, adaptation, distribution and reproduction in any medium or format, as long as you give appropriate credit to the original author(s) and the source, provide a link to the Creative Commons licence, and indicate if changes were made. The images or other third party material in this article are included in the article's Creative Commons licence, unless indicated otherwise in a credit line to the material. If material is not included in the article's Creative Commons licence and your intended use is not permitted by statutory regulation or exceeds the permitted use, you will need to obtain permission directly from the copyright holder. To view a copy of this licence, visit http://creativecommons.org/licenses/by/4.0/ The Creative Commons Public Domain Dedication waiver (http://creativecommons.org/publicdomain/zero/1.0/) applies to the data made available in this article, unless otherwise stated in a credit line to the data. 


\section{Background}

Hand, foot and mouth disease (HFMD) is one of the common infectious diseases caused by enteroviruses and can normally cause fever and rashes or ulcers on the hands, feet, mouth and other parts. Some patients can experience encephalitis, acute flaccid paralysis, respiratory infections, and myocarditis [1]. The epidemiological characteristics of HFMD are as follows: the population is generally susceptible; however, the disease mostly occurs in infants and young children under 5 years old [2, 3]. Children and adults often do not experience symptoms after infection, but they can spread the virus [4]. The virus is widespread and can have outbursts in all four seasons, especially in summer. When the disease breaks out, the young are often more susceptible to infection than adults.

HFMD has caused huge economic and disease burdens worldwide [5]. In 2011, the World Health Organization (WHO) issued a guide to clinical management and public health response for HFMD to tackle the disease [6]. The guide includes the epidemiology, virology, laboratory diagnosis, and pathogenesis of EV71 infection, along with prevention and control measurements. Globally, outbreaks of HFMD have been found in America [7], Spain [8], Brazil [9], and Finland [10]. However, the western Pacific region is most affected, namely, Japan [11], Thailand [12], Singapore [13], and Korea [14]. In China, the Chinese Center for Disease Control and Prevention $(\mathrm{CDC})$ included HFMD as a Class $\mathrm{C}$ reported notifiable infectious disease. In 2008, 31 provinces in China reported 488,955 cases of HFMD, 1165 were severe cases, and 126 died. The incidence and mortality rates were $37.01 / 100,000$ and $0.03 \%$, respectively [15]. Based on calculation, in 2018, 2,353,310 cases and 35 deaths due to HFMD were reported in China. The incidence and mortality rates were $169.41 / 100,000$ and $0.0025 / 100,000$, respectively. The average annual growth rate of HFMD incidence is $16.43 \%$. The incidence rate of HFMD in Shaanxi province from 2009 to 2018 was $140.04 / 100,000$, which is higher than the national reported incidence rate in the same period. Moreover, there are distinct differences within Shaanxi, as it is a special region that crosses three temperature zones. Hence, in this study, a spatial-temporal analysis of Shaanxi was performed to reveal the characteristics of the distribution of HFMD and to explore the meteorological determinants of HFMD.

Previous studies have been conducted to analyse the spatial-temporal characteristics of HFMD and the explanatory determinants. However, few studies researched the spatial-temporal situation in Shaanxi, China [16, 17]. Furthermore, different determinants have been explored in several studies, though no spatial determinants have been researched, meaning that all determinants included were derived from the local region rather than other surrounding regions. From the perspective of characteristics, Mao used seasonal decomposition, spatial autocorrelation and space scanning methods to analyse the all the intestinal infectious diseases in China. HFMD displayed a distinct increasing trend. The high-risk areas for HFMD were located in the Beijing-Tianjin-Tangshan (BTT) region and south China [18]. Hassel used largepanel datasets and a Bayesian phylogenetic approach to compare the molecular epidemiology and geographical spread patterns in Europe [19]. Bian researched the different pathogens of HFMD worldwide [20]. Regarding the determinants, the researchers mainly focused on individual, socio-ecological, geographical and meteorological factors. Lee used a general additive model (GAM) to explore the relationship between HFMD and geographical factors, as well as meteorological factors in East Asia [21]. Koh conducted a systematic review of the epidemiology of hand, foot and mouth disease in Asia and found that risk factors for HFMD included hygiene, age, gender and social contacts [22]. The research of Hao found that the incidence rate of HFMD was significantly associated with average temperature, relative humidity, vapor pressure, and wind speed. As can be seen from the above studies, spatial and temporal characteristics-related research has been performed in some regions of China using various methods such as time series, seasonal decomposition spatial autocorrelation and space scanning; however, there has been no specific study focusing on Shaanxi province. In addition, almost all the research analysed the meteorological factors related to HFMD. However, there is limited research discussing meteorological factors and the spatial dynamic patterns of HFMD. Determining the meteorological factors would essential for studying the relationship with the spatial dynamic patterns of HFMD.

In general, this study analysed the general distribution of HFMD from 2009 to 2018 using county-level and municipal data in Shaanxi, China. Then, the temporal and spatial characteristics of HFMD were evaluated. We then used a spatial econometric panel model to explore the spatial relationships between HFMD and related factors.

\section{Methods}

Study area

Shaanxi is located in central China between $105^{\circ} 29^{\prime}$ E$111^{\circ} 15^{\prime} \mathrm{E}$ and $31^{\circ} 42^{\prime} \mathrm{N}-39^{\circ} 35^{\prime} \mathrm{N}$, with the capital of Xi'an. Shaanxi has 10 municipal administrative divisions and 107 county administrative divisions. The terrain of Shaanxi Province is high in the north and south and low in the middle and is composed of plateaus, mountains, plains and basins. It covers the two major rivers: the Yellow River and the Yangtze River. Shaanxi has three climate types, namely moderate temperate monsoon 
climate, warm temperate monsoon climate and subtropical monsoon climate. In 2018, Shaanxi had a population of 38.844 million, with a GDP of 24.43832 billion yuan. Figure 1 displays a map of Shaanxi province.

\section{Data source and measurement of variables \\ Data source}

The county-level and municipal data of Shaanxi province from 2009 to 2018 were applied to research the spatio-temporal characteristics of HFMD and its meteorological determinants. The incidence rate of HFMD was obtained from the Shaanxi Provincial Center for Disease Control and Prevention (SXCDC). The meteorological data were obtained from the China Meteorological Data Service Center (CMDC), which is a subsidiary of the China Meteorological Administration (CMA). The monthly incidence rates of HFMD in all counties and meteorological data (Appendix 1) from all municipal cities were collected from 2009 to 2018. The descriptive statistics of HFMD are shown at the municipal level as a limitation of length, while temporal and spatial autocorrelation analyses were conducted using county-level data. Finally, the spatial econometric panel model used monthly municipal data. Table 1 displays the variables and data sources.

\section{Measurement of variables}

This study took the incidence rate of HFMD as a dependent variable and the meteorological variables, namely rainfall, temperature and humidity, as independent variables. Specifically, the incidence rates of HFMD is calculated through reported cases and potential population, which was normally obtained from SXCDC directly. The meteorological variables were obtained from CMDC through meteorological stations. Table 2 displays the variable measurements and descriptions.

\section{Temporal analysis method}

Time series were applied via a moving average method and are displayed through the plot. The moving average method was applied to smooth out short-term fluctuations and highlight longer-term trends or cycles [23]. In this article, the raw monthly incidence rate and estimated moving averages of 4 months (seasonally) and 12 months (yearly) are displayed in the plot.

\section{Spatial analysis method Spatial autocorrelation analysis}

There are two main laws in geography. The first one was proposed by Waldo Tobler: "Everything is associated with others, and close things are more related compared with distant things" [24]. The first law demonstrates the relationship between distance and association. Michael Goodchild came up with the second law, the law of spatial heterogeneity: "The separation of space accounts for the difference between regions, namely, heterogeneity, including spatial local heterogeneity and spatial stratified heterogeneity" [25]. The second law illustrates that the specific values of units were different from the surrounding regions, which could be regarded as hot or cold spots. Based on the laws of geography, spatial autocorrelation analysis was formulated to reveal the spatial dependence and hierarchical spatial enumeration. Appendix 2 provides a demonstration of different types of

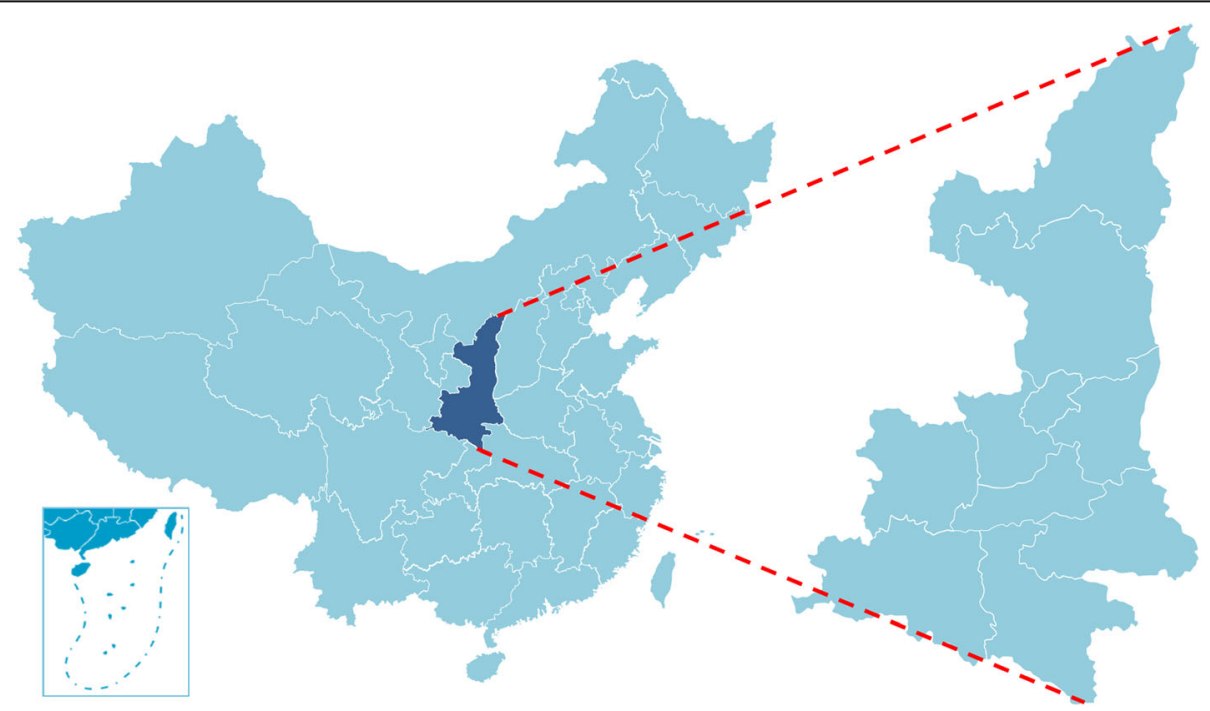

Fig. 1 The map of Shaanxi province, China (made through Microsoft PowerPoint, source of map: http://www.geodata.gov.cn/web/geo/index. html, under license without need for permission). *This figure was made by ourselves through Microsoft PowerPoint (Version 2013, Microsoft Crop, Redmond, WA, USA). The source of map was a public database, National Nature Resources and Geospatial basic information database of PRC (http://www.geodata.gov.cn/web/geo/index.html). This maps were under license without need for permission 
Table 1 Variables and data sources

\begin{tabular}{llll}
\hline Variables & Research subjects & Research period & Date resources \\
\hline HFMD & 10 municipal cities/107 counties & $2009.01-2018.12$ & SXCDC \\
Waterfall & 10 municipal cities & $2009.01-2018.12$ & CMDC \\
Temperature & 10 municipal cities & $2009.01-2018.12$ & CMDC \\
Humidity & 10 municipal cities & $2009.01-2018.12$ & CMDC \\
\hline
\end{tabular}

spatial cluster situations. Each circle represents the variables in specific units, and the circles are associated with each other. The red circles represent indicators with higher values, while the blue circles denote the lower values. The left graph, demonstrating the positive spatial autocorrelation, shows the pattern of clusters with similar values, namely, the red circles tend to be near to each other, and the blue circles surround each other. There is no spatial autocorrelation in the middle graph due to the random distribution of high and low values. Negative spatial autocorrelation is found in the right graph, which means that the high values are surrounded by the low values.

The Moran's I is one of the most commonly used indicators considering spatial autocorrelation analysis, which consists of global and local Moran's I. Global Moran's I is a reflection of the first law, measuring the spatial dependence of the whole research region, while as a transformation of the second law, the local Moran's I reflects the regional differences. In our study, the global and local Moran's I findings reveal the whole-level spatial distribution characteristics of the study region and specific cluster regions in the research area, respectively [26].

In this study, the value of global Moran's I, ranging from -1 to 1 , reflects the overall spatial distribution of HFMD in Shaanxi province. When the index is near 1, a positive spatial autocorrelation is detected [27, 28]. The counties with high incidence rates of HFMD tend to cluster. A zero means that there is no spatial autocorrelation of HFMD, illustrating high and low values scattered randomly in Shaanxi. When the values are distributed around -1 , a negative spatial autocorrelation is observed, indicating that counties with high and low values border each other. The equation of global Moran's I is as follows:

$$
\text { Global Moran' }{ }^{\prime} I=\frac{n \sum_{i=1}^{n} \sum_{j=1}^{n} W_{i j}\left(X_{i}-\bar{X}\right)\left(X_{j}-\bar{X}\right)}{\sum_{i=1}^{n} \sum_{j=1}^{n} W_{i j}\left(X_{i}-\bar{X}\right)^{2}}
$$

Where $X_{i}$ is the incidence rate of HMFD in county $\mathrm{i}$ and $j$. The $\bar{X}$ is the mean value of the incidence rate of HFMD in Shaanxi. The difference between the mean and absolute values of incidence rate is crucial in determining the positive or negative effects. $n$ is the number of all the counties in Shaanxi. $W_{i j}$ is an important tool in spatial modelling, as it quantifies the spatial dependence between observations, which is normally expressed as an $\mathrm{n} \times \mathrm{n}$ non-negative matrix $\mathrm{W}$ :

$$
W_{i j}=\left[\begin{array}{ccc}
w_{11} & \cdots & w_{1 n} \\
\vdots & \ddots & \vdots \\
w_{n 1} & \cdots & w_{n n}
\end{array}\right]
$$

Where $\mathrm{n}$ is the number of spatial units; $W_{i j}$ represents the spatial dependency relationship between region $i$ and region $j$. The larger the weight value, the stronger the spatial dependency between regions. The spatial weight matrix was constructed based on a contiguity relationship. Therefore, the value on the main diagonal of the matrix is zero, which means that each area is not adjacent to itself, namely, $W_{i j}=0$. At the same time, if areas $\mathrm{i}$ and $\mathrm{j}$ are adjacent, then $W_{i j}=W_{j i}$. The spatial weight matrix is symmetrical.

Regarding the local Moran's I, a positive value of the index represents the similarity of region, which means that the regions with high or low incidence rates of HFMD cluster within the same category, while a negative value indicates the opposite, that is, the counties with high incidence rates tended to be near regions with low incidence rates. Based on the value and the significance level, the clusters could be classified as four types, namely, High-high $(\mathrm{HH}$, the regions with high incidence

\begin{tabular}{|c|c|c|c|}
\hline Variables type & Variable name & Measurement & Description \\
\hline $\begin{array}{l}\text { Dependent } \\
\text { variables }\end{array}$ & HFMD & $\begin{array}{l}\text { The incidence rate } \\
\text { of HFMD }\end{array}$ & $\begin{array}{l}\text { Number of new cases of HFMD in population during a certain period of time / Number } \\
\text { of people exposed during the same period }\end{array}$ \\
\hline \multirow{3}{*}{$\begin{array}{l}\text { Independent } \\
\text { variables }\end{array}$} & Waterfall & Average monthly rainfall & Add up the average daily rainfall and divide by the number of days in the month \\
\hline & Temperature & $\begin{array}{l}\text { Monthly average } \\
\text { temperature }\end{array}$ & Add up the average daily temperature and divide by the number of days in the month \\
\hline & Humidity & $\begin{array}{l}\text { Monthly average relative } \\
\text { humidity }\end{array}$ & Add up the average daily humidity and divide by the number of days in the month \\
\hline
\end{tabular}

Table 2 Variables measurements and description 
rates are surrounded with other high incidence rate regions), High-low (HL), Low-high (LH), and Low-low (LL). The equation of local Moran's I is as follows [26]:

$$
\text { Local Moran's } I=\frac{x_{i}-\bar{x}}{m_{0}} \sum_{j} W_{i j}\left(X_{j}-\bar{X}\right) m_{0}=\sum_{i}\left(X_{i}-\bar{X}\right)^{2} / n .
$$

Where $m_{0}$ is a constant across all county-units; the explanation of other parameters is the same as with the global Moral's I. To further demonstrate the statistically significant level of the incidence rate of HFMD, a map displaying the counties whose local Moran's I has significant results is presented. The map is also known as a LISA map.

\section{Spatial econometric panel model}

In this study, the Spatial Lag Panel Model (SLPM), Spatial Error Panel Model (SEPM), and Spatial Durbin Panel Model (SDPM) were introduced to reveal the relationship between the HMFD and meteorological factors based on the following model derived from the measurement of variables [29-32]. The logarithm of the variable would not change the nature and correlation of the data, but it would compress the scale of the variable. After taking the logarithm of the variables, the data was more stable, and the collinearity and heteroscedasticity of the model were also weakened. In this article, the logarithm of waterfall played an important in weakening the heteroscedasticity. Besides, the temperature had negative number and the unit of humidity is percentage, which is not suitable for logarithm change, so the final model was as follows:

$$
\begin{aligned}
\ln (\text { HFMD })_{i t}= & \alpha+\beta_{1} \ln \left(\text { waterfall }_{i t}\right. \\
& +\beta_{2} \text { temperature }_{i t}+\beta_{3} \text { humidity }_{i t} \\
& +\varepsilon_{i j} i \\
= & 1,2 \ldots 107 ; t=2009,2010 \ldots 2018
\end{aligned}
$$

Where the $i$ represents the 107 county-units $(i=1,2 \ldots$ $107) ; t$ means the time variable $(t=2009,2010 . . .2018) ; \alpha$ denotes the constant term and $\varepsilon_{i j}$ represents the error term. The SLPM is used to analyse the influence of dependent variables from the neighbouring counties by adding the spatial lag term of the dependent variable into the independent variable. The spatial dependence can be reflected as an error term, namely, missing variables in the model have a spatial correlation with HMFD, or unobservable random variables have spatial correlations with HMFD. The SEPM is applied in such circumstances. The SDPM is useful in reflecting the influence on specific regions from surrounding regions. However, although the SDPM can reveal the relationship between dependent and independent variables inside and outside the local region, the coefficients of SDPM cannot be directly explained, as the effects due to the derivative of $y$ correspondence to $x$ usually do not equal $\beta_{k}$. Hence, the effects of the coefficient can be decomposed into direct and spill-over effects.

After understanding the functions of all the spatial econometric panel models, a standard model selection strategy is established. The procedures can be divided into four steps. In the first step, the Moran's I or LM test is introduced to examine the spatial autocorrelation, namely, the availability of conducting spatial analysis methods. In the second step, the Wald test and the LR test are used to choose the SLPM, SEPM or SPDM. In the third step, the Hausman test is applied to determine whether a fixed effect model or a random effect model should be used. If a fixed effect model is used, the last step is introduced to determine the application of fixed effects (time, individual or both). If it is fixed effect model, the last step were introduced to determine individual fixed effects (controlling the "space-specific, timeinvariant" variables, which are excluded from the model) or time effects (controlling the "time-specific, spaceinvariant" variables, which are excluded from the model) or both fixed effects (controlling the above two), and it would be chosen according to the sample size and time.

\section{Software tools}

The time series analysis used Microsoft Excel (Version 2013, Microsoft Crop, Redmond, WA, USA) for visualization. The spatial autocorrelation analysis and the spatial weight matrix were analysed by GeoDa (Version 1.8.61, the University of Chicago, Chicago, IL, USA). STATA 15.0 (Version 15.0, StataCorp, College Station, TX, USA) was employed to calculate the spatial panel models. Finally, ArcGIS (Version 10.0, ESRI Inc., Redlands, CA, USA) was used to visualize the results.

\section{Results}

\section{The prevalence of HFMD}

We listed the morbidity of HFMD reported in each municipal unit in Shaanxi from 2009 to 2018. Table 3 provides a descriptive analysis of HFMD, containing the average, maximum and minimum values of morbidity at the municipal level from 2009 to 2018. The municipal administrative divisions were classified as northern, central and southern Shaanxi according to the geographical difference.

As shown in the analysis of the descriptive summary provided in Table 4, Central Shaanxi had the highest incidence rate compared with the northern and southern units, with an average of 13.87 per 100,000 individuals in 2018 , while the morbidity averages in the northern and southern units were 12.55 per 100,000 individuals and 6.68 per 100,000 individuals, respectively. At the same time, the incidence in the southern region was relatively high in comparison with the northern one. The central 
Table 3 Descriptive statistics of the variables

\begin{tabular}{|c|c|c|c|c|c|c|}
\hline Variable & Obs & Mean & Std. Dev. & Min. & Max. & Units \\
\hline HFMD & 1200 & 9.449 & 12.335 & 0 & 100.0865 & $/ 10,000$ person \\
\hline waterfall & 1200 & 56.523 & 60.215 & 0 & 367.05 & $\mathrm{~mm}$ \\
\hline temperature & 1200 & 12.211 & 9.358 & -12.175 & 30.5 & ${ }^{\circ} \mathrm{C}$ \\
\hline humidity & 1200 & 65.642 & 12.512 & 29 & 91 & $\%$ \\
\hline
\end{tabular}

region showed peak of morbidity in 2015, compared to peaks in 2018 and 2014 for the northern and southern units, respectively. When considering the municipal cities, Xi'an, the capital, had the most severe situation, with an average incidence of 20.92 per 100,000 individuals during the research period. Weinan, a city in central Shaanxi, experienced a relatively serious situation in addition to Xi'an. Yan'an and Yulin, cities in northern Shaanxi, were regarded as the least affected areas.

\section{Temporal analysis}

Time series analysis plots are shown in Fig. 2. In the trend analysis, there was no distinct trend during the research period. Relatively high incidence rates were witnessed in 2010, 2012, 2013, 2014, 2015 and 2018. In contrast, relatively low incidence rates were found in 2009, 2011, 2016 and 2017. In the seasonal analysis, the high-incidence seasons of HFMD in the study period were summer and autumn according to the different peaks throughout the years.

\section{Spatial autocorrelation analysis}

The spatial autocorrelation analysis was analysed from two perspectives: global and local spatial autocorrelation. The function of global spatial autocorrelation was to detect whether the incidence rate of Shaanxi tended to cluster from 2009 to 2018. The function of local spatial autocorrelation was to differentiate the type of cluster.

\section{Global spatial autocorrelation}

Table 5 illustrates the Moran's I and the significance level of HFMD from 2009 to 2018. In consideration of the significance results, all the Moran's I values of HFMD were significant. Table 5 also reports the significance levels of all counties. Considering 2009 as an example, the number of counties with a 0.001 significance level was 6 , while 5 and 15 counties corresponded to significance levels of 0.01 and 0.05 , respectively. Considering the global Moran's I, the index of HFMD ranged from 0.177130 to 0.514433 throughout the 10 years, without a distinct increasing or decreasing trend. In general, there was an evident spatial cluster of HFMD during the study period, allowing subsequent analysis of the local spatial autocorrelation.

\section{Local spatial autocorrelation}

Figure 3 displays the incidence rate of HFMD in all counties of Shaanxi from 2009 to 2018. The incidence rates were classified into five categories based on the minimum and maximum values. The classification method was natural segmentation using ArcGIS. The deeper the red colour, the higher the incidence rate. Considering morbidity in 2009 as an example, the minimum and maximum values were 0.00 per 100,000 individuals and 29.28 per 100,000 individuals, respectively, with categories divided into $0.00-2.08,2.08-4.78,4.78-$ $8.91,8.91-15.02$, and $15.02-29.28$. We found that central Shaanxi and counties in the northwest had the highest detected incidence rates. It should also be noted that the classifications of HFMD were different due to the high variation throughout the research period. Using the same classification method would lead to no differences detected between counties in some years. In general, the hierarchical maps only illustrate the relative relationship within a single year. Appendix 3 displays the map with same legend for different years.

Figure 4 shows the spatial cluster of morbidity of HFMD and reveals the geographical variation from 2009 to 2018. The HH cluster in central Shaanxi was witnessed throughout the entire research period (Xi'an, Xianyang and Weinan). Some southern regions adjacent to the central areas also showed evidence of the $\mathrm{HH}$ cluster. The counties susceptible to the HH cluster increased constantly. The agglomeration blocks were gradually extended to two or three. Conversely, the HL clusters were randomly scattered in Shaanxi province, mostly in the northern region. The counties included Jiaxian, Ganquan, Zizhou, Dingbian and other counties. The counties involved in the LH cluster were mainly located in the surrounding area of central Shaanxi. Regarding the LL cluster northern Shaanxi (Yan'an, Yulin) was involved. Western central Shaanxi (Baoji city) also experienced the LL cluster in 2017.

\section{Empirical results of spatial panel models}

Table 6 displays all the estimation results of the spatial panel econometric models for HFMD. The model selection process is shown in Fig. 5 and demonstrated that the best model is SDPM, with individual- and time-based fixed effects. Among all three models, the application of SDPM requires 
Table 4 The total incidence rates of HFMD in Shaanxi from 2009 to $2018(1 / 100,000)$

\begin{tabular}{|c|c|c|c|c|c|c|c|c|c|c|c|c|}
\hline Region & & 2009 & 2010 & 2011 & 2012 & 2013 & 2014 & 2015 & 2016 & 2017 & 2018 & Average \\
\hline \multirow[t]{3}{*}{ Xi'an } & IN & 12.43 & 27.12 & 12.20 & 24.83 & 19.42 & 24.50 & 27.97 & 21.00 & 14.07 & 25.65 & 20.92 \\
\hline & Min. & 3.80 & 8.76 & 2.22 & 9.35 & 7.07 & 13.01 & 16.27 & 9.99 & 5.97 & 8.42 & 8.49 \\
\hline & Max. & 27.93 & 55.30 & 20.86 & 41.83 & 36.16 & 42.94 & 45.68 & 38.46 & 26.81 & 46.47 & 38.24 \\
\hline \multirow[t]{3}{*}{ Ваојі } & IN & 3.91 & 8.61 & 5.20 & 9.02 & 7.34 & 11.18 & 8.65 & 5.77 & 3.90 & 13.66 & 7.72 \\
\hline & Min. & 0.63 & 0.77 & 0.37 & 4.39 & 1.18 & 5.81 & 2.63 & 2.37 & 1.46 & 4.42 & 2.40 \\
\hline & Max. & 12.26 & 18.34 & 17.55 & 28.84 & 20.00 & 25.91 & 14.09 & 16.81 & 8.09 & 31.32 & 19.32 \\
\hline \multirow[t]{3}{*}{ Tongchuan } & IN & 4.52 & 5.71 & 3.75 & 8.63 & 6.87 & 8.90 & 8.42 & 5.61 & 4.27 & 7.84 & 6.45 \\
\hline & Min. & 1.61 & 3.48 & 2.41 & 5.52 & 4.73 & 4.78 & 5.75 & 3.16 & 3.57 & 4.86 & 3.99 \\
\hline & Max. & 8.45 & 9.75 & 4.30 & 12.00 & 9.93 & 12.47 & 11.04 & 8.65 & 5.82 & 13.75 & 9.62 \\
\hline \multirow[t]{3}{*}{ Weinan } & IN & 9.04 & 14.94 & 12.52 & 12.10 & 14.22 & 20.28 & 18.81 & 13.38 & 9.25 & 10.35 & 13.49 \\
\hline & Min. & 1.54 & 3.56 & 2.32 & 4.24 & 3.58 & 8.25 & 5.48 & 2.08 & 3.77 & 2.44 & 3.73 \\
\hline & Max. & 29.28 & 27.02 & 26.00 & 22.63 & 37.94 & 37.29 & 41.68 & 25.75 & 15.30 & 18.05 & 28.09 \\
\hline \multirow[t]{3}{*}{ Xianyang } & IN & 6.61 & 9.23 & 4.41 & 14.99 & 10.65 & 15.90 & 12.79 & 10.50 & 6.02 & 11.86 & 10.30 \\
\hline & Min. & 1.79 & 2.04 & 0.49 & 3.40 & 1.82 & 5.53 & 5.68 & 4.38 & 2.79 & 4.53 & 3.25 \\
\hline & Max. & 19.20 & 19.02 & 13.07 & 32.67 & 24.57 & 29.53 & 27.35 & 20.44 & 10.44 & 18.12 & 21.44 \\
\hline Central Shaanxi & IN & 7.30 & 13.12 & 7.62 & 13.91 & 11.70 & 16.15 & 15.33 & 11.25 & 7.50 & 13.87 & 11.78 \\
\hline \multirow[t]{3}{*}{ Shangluo } & IN & 2.91 & 7.47 & 4.63 & 9.95 & 7.99 & 9.09 & 11.02 & 6.28 & 7.14 & 9.84 & 7.63 \\
\hline & Min. & 1.20 & 3.28 & 1.47 & 2.84 & 2.85 & 1.55 & 2.11 & 1.56 & 1.51 & 4.64 & 2.30 \\
\hline & Max. & 6.43 & 13.88 & 8.88 & 20.28 & 13.16 & 20.93 & 24.35 & 11.94 & 15.15 & 21.36 & 15.64 \\
\hline \multirow[t]{3}{*}{ Ankang } & IN & 3.78 & 7.83 & 3.16 & 7.69 & 10.79 & 9.47 & 11.82 & 14.61 & 7.32 & 16.58 & 9.31 \\
\hline & Min. & 0.07 & 0.70 & 0.11 & 1.08 & 0.78 & 1.05 & 0.49 & 4.13 & 4.07 & 4.04 & 1.65 \\
\hline & Max. & 12.05 & 11.25 & 13.77 & 18.53 & 69.52 & 21.04 & 19.48 & 31.35 & 16.67 & 21.51 & 23.52 \\
\hline \multirow[t]{3}{*}{ Hanzhong } & IN & 1.78 & 12.43 & 2.89 & 8.90 & 11.54 & 12.32 & 7.76 & 8.90 & 7.02 & 11.22 & 8.48 \\
\hline & Min. & 0.00 & 0.72 & 0.30 & 2.45 & 2.74 & 3.88 & 1.53 & 2.72 & 0.82 & 4.67 & 1.98 \\
\hline & Max. & 5.34 & 21.40 & 7.10 & 15.15 & 22.48 & 24.13 & 14.51 & 21.83 & 11.59 & 18.67 & 16.22 \\
\hline Southern Shaanxi & IN & 2.82 & 9.24 & 3.56 & 8.85 & 10.11 & 10.29 & 10.20 & 9.93 & 7.16 & 12.55 & 8.47 \\
\hline \multirow[t]{3}{*}{ Yan'an } & IN & 2.85 & 2.86 & 2.96 & 1.15 & 3.70 & 10.04 & 4.85 & 4.13 & 10.07 & 5.72 & 4.83 \\
\hline & Min. & 0.11 & 0.14 & 0.21 & 0.20 & 0.23 & 1.02 & 0.49 & 0.46 & 1.09 & 0.34 & 0.43 \\
\hline & Max. & 11.22 & 17.40 & 17.52 & 8.98 & 16.22 & 43.32 & 25.21 & 21.29 & 32.25 & 22.08 & 21.55 \\
\hline \multirow[t]{3}{*}{ Yulin } & IN & 4.01 & 4.87 & 4.26 & 4.08 & 4.27 & 6.08 & 9.36 & 4.29 & 4.82 & 7.64 & 5.37 \\
\hline & Min. & 0.27 & 0.62 & 0.43 & 0.75 & 0.86 & 1.10 & 0.99 & 0.50 & 0.84 & 0.93 & 0.73 \\
\hline & Max. & 17.49 & 12.88 & 19.20 & 12.08 & 18.22 & 14.84 & 45.07 & 8.82 & 8.90 & 17.63 & 17.51 \\
\hline Northern Shaanxi & IN & 3.43 & 3.87 & 3.61 & 2.62 & 3.99 & 8.06 & 7.11 & 4.21 & 7.45 & 6.68 & 5.10 \\
\hline Sum & IN & 6.49 & 12.94 & 7.07 & 12.87 & 11.68 & 15.55 & 15.17 & 11.62 & 8.68 & 14.58 & 11.67 \\
\hline
\end{tabular}

Note: IN Incidence rate, Min. Minimum, Max. Maximum

multiple conditions, while SLPM and SEPM are simplified models of SDPM to some extent. Therefore, the first step requires the use of the Wald and LR tests to determine whether SDPM can be simplified to SLPM and SEPM (null hypothesis). In this study, all chi2 test results were significant; therefore, the null hypothesis was refused. The next step is to use the Hausman test to determine whether to use a fixed effect model or a random effect model. The fixed model was chosen if the chi2 test result was a negative number. Finally, time, individual or both fixed models were selected according to the test results.

According to the empirical results, the value $\rho$ of the best model was significant and negative, which implied the existence of negative spillover spatial effects. The results of empirical results could not be interpreted directly. Thus, we analysed the incidence rate of HFMD and its determinants from direct and spill-over effects. The direct effects mean the influence from the 


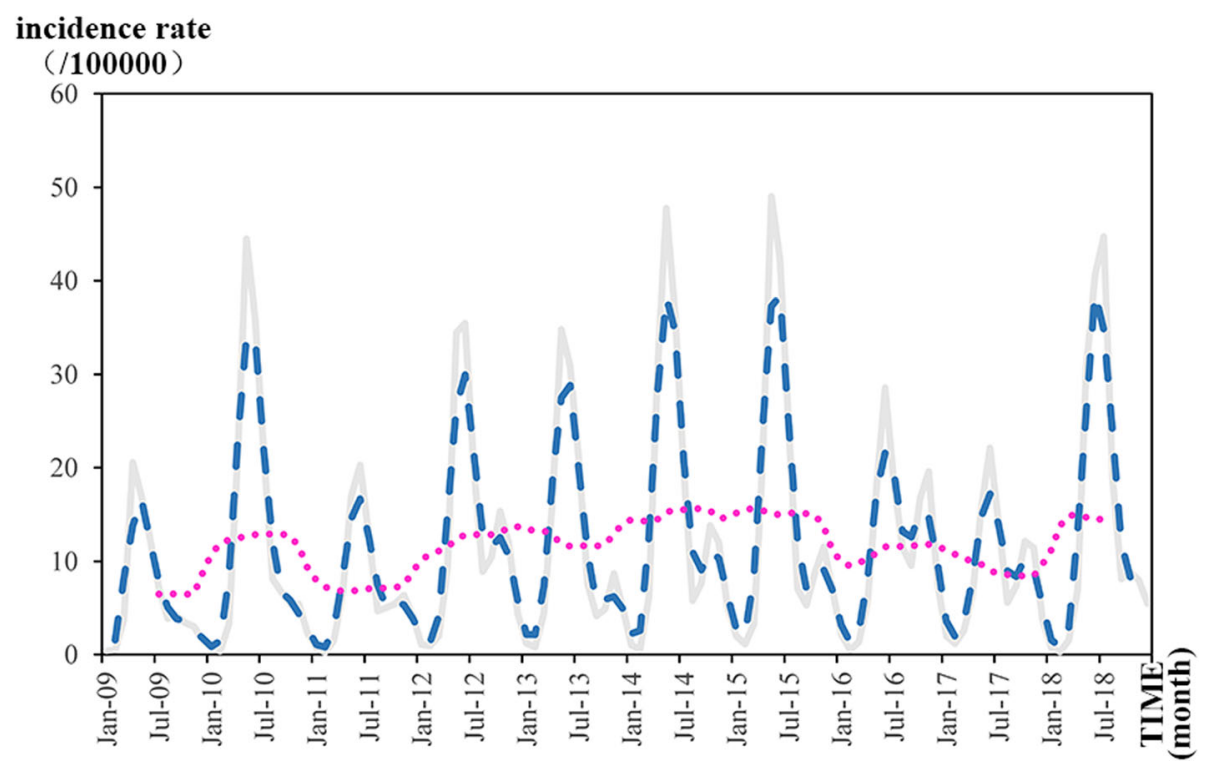

Fig. 2 Time series analysis plots (made through Microsoft Excel). Note: The incidence rate (gray lines) were calculated through the incidence rate and population. Moving average data of 3 months (blue lines) and 12 months (pink lines) were shown. *This figure was made by ourselves through Microsoft Excel (Version 2013, Microsoft Crop, Redmond, WA, USA)

determinants of local region such as the effect of meteorological factors in Xi'an to its incidence rate of HFMD, whereas the spillover effects reflect the influence from surrounding areas such as the effect of meteorological factors in Xi'an to incidence rate of HFMD in Weinan (an adjacent region).

\section{Decomposing the direct and spill-over effects}

Tables 7 and 8 report the direct and spill-over effects independent of HFMD. Regarding the direct effects shown by the best model, rainfall had a positive association with the incidence rate of HFMD: with a $1 \%$ increases of rainfall in affected counties, the incidence rate of HFMD

Table $\mathbf{5}$ Global spatial autocorrelation analysis and significance test results

\begin{tabular}{lllllll}
\hline Year & Moran's I & $\boldsymbol{p}$-value & $\mathbf{p}-\mathbf{0 . 0 5}$ & $\mathbf{P}-\mathbf{0 . 0 1}$ & $\mathbf{p}-\mathbf{0 . 0 0 1}$ & $\mathbf{p}-\mathbf{0 . 0 0 0 1}$ \\
\hline 2009 & $0.270299^{* *}$ & 0.00170 & 15 & 5 & 6 & 0 \\
2010 & $0.514433^{* * *}$ & 0.00001 & 8 & 9 & 7 & 5 \\
2011 & $0.386398^{* * *}$ & 0.00001 & 13 & 11 & 3 & 1 \\
2012 & $0.500738^{* * *}$ & 0.00001 & 7 & 11 & 11 & 4 \\
2013 & $0.177130^{* *}$ & 0.00476 & 20 & 8 & 3 & 2 \\
2014 & $0.271359^{* * *}$ & 0.00002 & 21 & 11 & 2 & 0 \\
2015 & $0.328566^{* * *}$ & 0.00001 & 20 & 9 & 5 & 0 \\
2016 & $0.311582^{* * *}$ & 0.00002 & 12 & 12 & 8 & 2 \\
2017 & $0.237429^{* * *}$ & 0.00054 & 19 & 9 & 2 & 0 \\
2018 & $0.352848^{* * *}$ & 0.00001 & 14 & 11 & 6 & 3 \\
\hline
\end{tabular}

Note: *a $10 \%$ level of statistical significance; **a $5 \%$ level of statistical significance; ***a $1 \%$ level of statistical significance would increase $0.071 \%$, while there was no significance when considering temperature and humidity.

Spill-over effects could be explained from two perspectives. When the coefficient was positive, the independent variables of one specific unit could positively affect the HFMD of surrounding counties; conversely, a negative coefficient would be interpreted as a negative association with the HMFD of the surrounding region. According to our analysis, all the independent variables displayed positive relationships with HFMD, which demonstrated that increases in rainfall, temperature and humidity in one county would increase the incidence rate of HFMD in adjacent counties. Regarding rainfall, a 1\% increase would cause a $0.218 \%$ increase in the incidence rate of HFMD. With an increase in temperature of $1^{\circ} \mathrm{C}$, the incidence rate of HFMD of the surrounding counties would increase $0.450 \%$. Considering humidity, a $0.045 \%$ incidence increase in the surrounding region could correspond to a $1 \%$ increase in humidity.

\section{Discussion}

In recent years, HFMD has become an important public health problem worldwide. Since the 1990s, the disease has frequently broken out in the Asian-Pacific region. Large-scale HFMD outbreaks have occurred in China, with many severe cases and deaths. Shaanxi is a special province with three different climate zones; thus, it was chosen as the research area. In this article, we applied temporal and spatial analysis methods to display the characteristics of the HFMD incidence rate in Shaanxi at the county level from 2009 to 


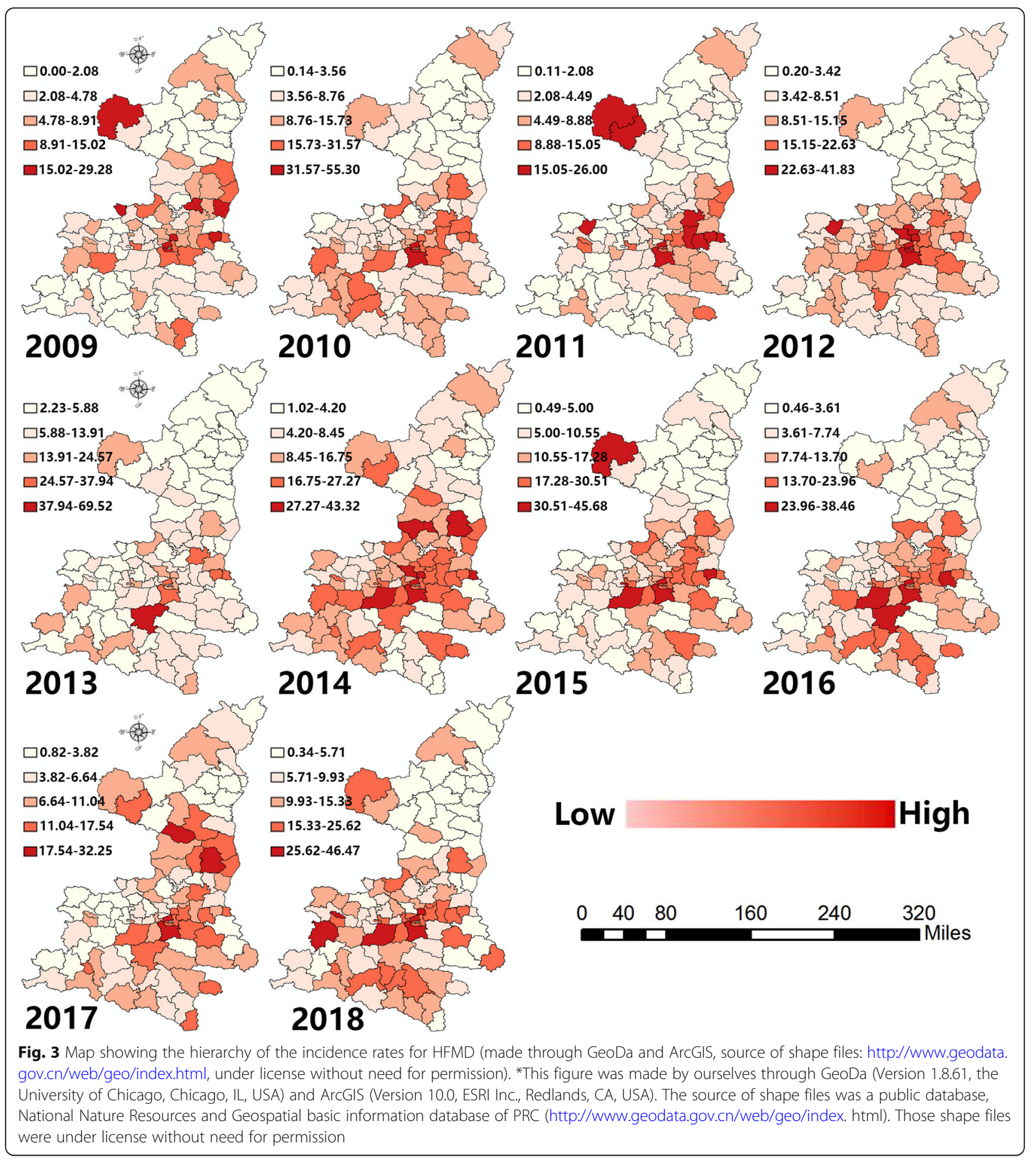

2018. Then, spatial econometric panel models were used to analyse the relationship between HFMD and meteorological factors. The evidence provided insights into potential solutions to diminish the disease incidence.

Based on the reported incidence rate of HFMD in Shaanxi from 2009 to 2018. The incidence rate of
HFMD fluctuated during the research period. There was no distinct trend in the period of the investigation. In China, the targeted polices of HFMD had limited influence on the control and prevention of the disease. At the same time, the meteorological and socioeconomic factors changed during the research period. Meteorological factors such as temperature and humidity can 


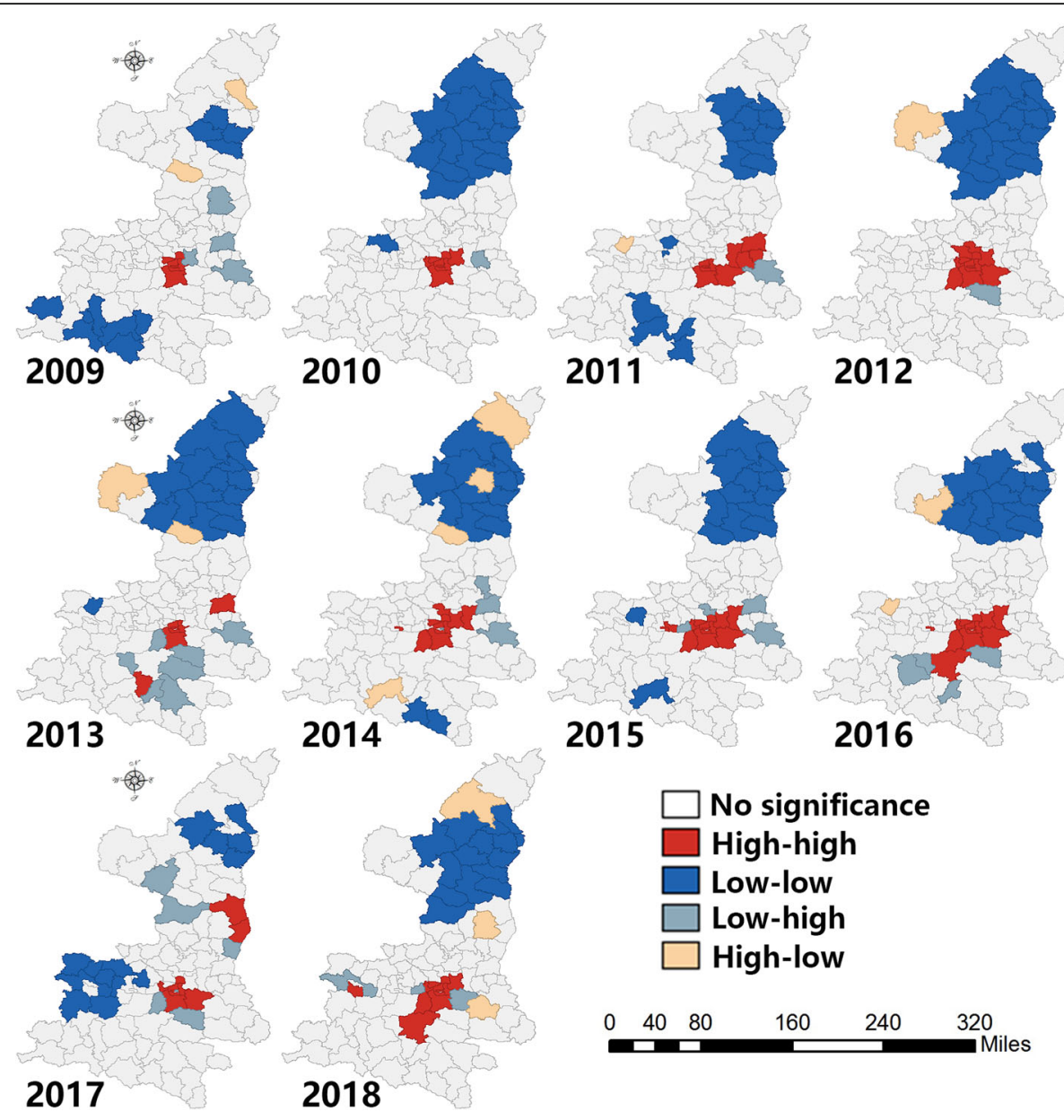

Fig. 4 The spatial clusters of incidence rate of HFMD (made through GeoDa and ArcGIS, source of shape files: http://www.geodata.gov.cn/web/ geo/index.html, under license without need for permission). *This figure was made by ourselves through GeoDa (Version 1.8.61, the University of Chicago, Chicago, IL, USA) and ArcGIS (Version 10.0, ESRI Inc., Redlands, CA, USA). The source of shape files was a public database, National Nature Resources and Geospatial basic information database of PRC (http://www.geodata.gov.cn/web/geo/index. html). Those shape files were under license without need for permission

directly affect the reproduction of pathogens and their survival time in the environment. Moreover, the children of migration accounted for seven-tenths of the total incidence of HFMD, at the same time, there was a predisposition associated with the condition of the systemic state of the adult, although it may appeared in immunocompetent adults. The immigration scale varied during the study period, which may could explain the fluctuation of incidence rate. Fang conducted a research about spatial characteristics of immigration of Shaanxi province, revealing that the immigration in central Shaanxi is HL cluster, which may could explain the situation of HFMD in that region [33]. Considering the seasonal trends, summer and autumn were the high-occurrence seasons, and the results were the same as the research result of $\mathrm{Li}$ [34], which was that the summer and autumn are the main outbreak seasons throughout China. The same results have also been found in Sichuan province [35], Shandong province [36], Guangxi province [37], Guangdong province [38], and Zhejiang province [39]. On one hand, in summer and autumn, the monsoon climate of China brings much precipitation, along with high temperature and high humidity, which could form a suitable environment for pathogen growth. On the other hand, the hot and humid environment can influence people's lifestyle. For example, people are excessively depending on air conditioning to create a comfortable indoor environment now, but it could cause some health problems in a long run [40]. In general, as the highest season of HFMD incidence, summer should be paid more attention.

In consideration of HFMD, a spatial autocorrelation could be detected in Shaanxi according to the significant global Moran's I. In fact, a spatial autocorrelation of HFMD has been found in other counties in southeast 
Table 6 Estimation results of spatial panel econometric models for HFMD

\begin{tabular}{|c|c|c|c|c|c|c|}
\hline Variable & $\begin{array}{l}\text { SDPM with } \\
\text { individual Fixed } \\
\text { Effects }\end{array}$ & $\begin{array}{l}\text { SDPM with } \\
\text { Time Fixed } \\
\text { Effects }\end{array}$ & $\begin{array}{l}\text { SDPM with individual and } \\
\text { Time Fixed Effects } \\
\text { (Best model) }\end{array}$ & $\begin{array}{l}\text { SDPM with } \\
\text { Random Effects }\end{array}$ & $\begin{array}{l}\text { SEPM with individual } \\
\text { and Time Fixed } \\
\text { Effects }\end{array}$ & $\begin{array}{l}\text { SLPM with individual } \\
\text { and Time Fixed } \\
\text { Effects }\end{array}$ \\
\hline Ln (waterfall) & $0.115^{* * *}(3.79)$ & $\begin{array}{l}0.129^{* * *} \\
(4.13)\end{array}$ & $0.064^{* *}(2.28)$ & $0.119^{* * *}(3.90)$ & $0.043(1.48)$ & $0.048(1.68)$ \\
\hline temperature & $0.033(0.71)$ & $0.009(0.59)$ & $0.074(1.87)$ & $0.020(0.49)$ & $0.220^{* * *}(7.07)$ & $0.216^{* * *}(6.82)$ \\
\hline humidity & $0.005(0.48)$ & $\begin{array}{l}-0.021 \text { *** } \\
(-3.73)\end{array}$ & $0.005(0.60)$ & $0.001(0.12)$ & $0.021^{* * *}(2.90)$ & $0.020 * * *(2.80)$ \\
\hline $\begin{array}{l}W \times \ln \\
\text { (waterfall) }\end{array}$ & $\begin{array}{l}-0.110^{* * *} \\
(-3.08)\end{array}$ & $\begin{array}{l}-0.206^{* * * *} \\
(-3.78)\end{array}$ & $-0.224^{* * *}(-4.55)$ & $\begin{array}{l}-0.114^{* * *} \\
(-3.19)\end{array}$ & & \\
\hline $\begin{array}{l}W \times \\
\text { temperature }\end{array}$ & $0.025(0.53)$ & $\begin{array}{l}0.189 * * * \\
(7.52)\end{array}$ & $0.047^{* * *}(3.12)$ & $0.038(0.93)$ & & \\
\hline $\mathrm{W} \times$ humidity & $-0.004(-0.37)$ & $\begin{array}{l}0.079^{* * *} \\
(6.36)\end{array}$ & $0.481^{* * *}(6.11)$ & $-0.000(-0.01)$ & & \\
\hline$\rho$ & $0.527^{* * *}(23.08)$ & $-0.047(-1.28)$ & $-0.082^{*}(-2.23)$ & $\begin{array}{l}0.525^{* * *} \\
(22.94)\end{array}$ & & $-0.050(-1.36)$ \\
\hline$\lambda$ & & & & & $-0.066(-1.76)$ & \\
\hline LLR & -1947.0557 & -1821.5605 & -1673.4282 & -1968.8335 & -1698.6342 & -1699.2869 \\
\hline $\mathrm{Rw}^{2}$ & 0.3798 & 0.3555 & 0.3760 & 0.3792 & 0.3755 & 0.3755 \\
\hline $\mathrm{Rb}^{2}$ & 0.3354 & 0.4717 & 0.3557 & 0.3798 & 0.1764 & 0.1688 \\
\hline$R^{2}$ & 0.3681 & 0.3593 & 0.3693 & 0.3682 & 0.3514 & 0.3502 \\
\hline Obs & 1200 & 1200 & 1200 & 1200 & 1200 & 1200 \\
\hline
\end{tabular}

Note: Standard error in parentheses, ${ }^{* * *} p<0.01,{ }^{* *} p<0.05,{ }^{*} p<0.1$

Asia, such as Thailand [41], Vietnam [42], and Malaysia [43]. Hot spots were witnessed in central Shaanxi (Guanzhong plain), which is a relatively rich area in Shaanxi. With the highly developed industrialization and the urban sprawl, the urban living environment in began to change. The large migrant population normally had a poor health lifestyle and poor knowledge of epidemic prevention measures. Thus, some high clusters were found on the border between Shaanxi and Shanxi. Cold spots were detected in northern Shaanxi (loess plateau). The northern region is relatively poor, with a population with low mobility compared with the central areas. At the same time, the meteorological environment was not suitable for the growth of pathogens.

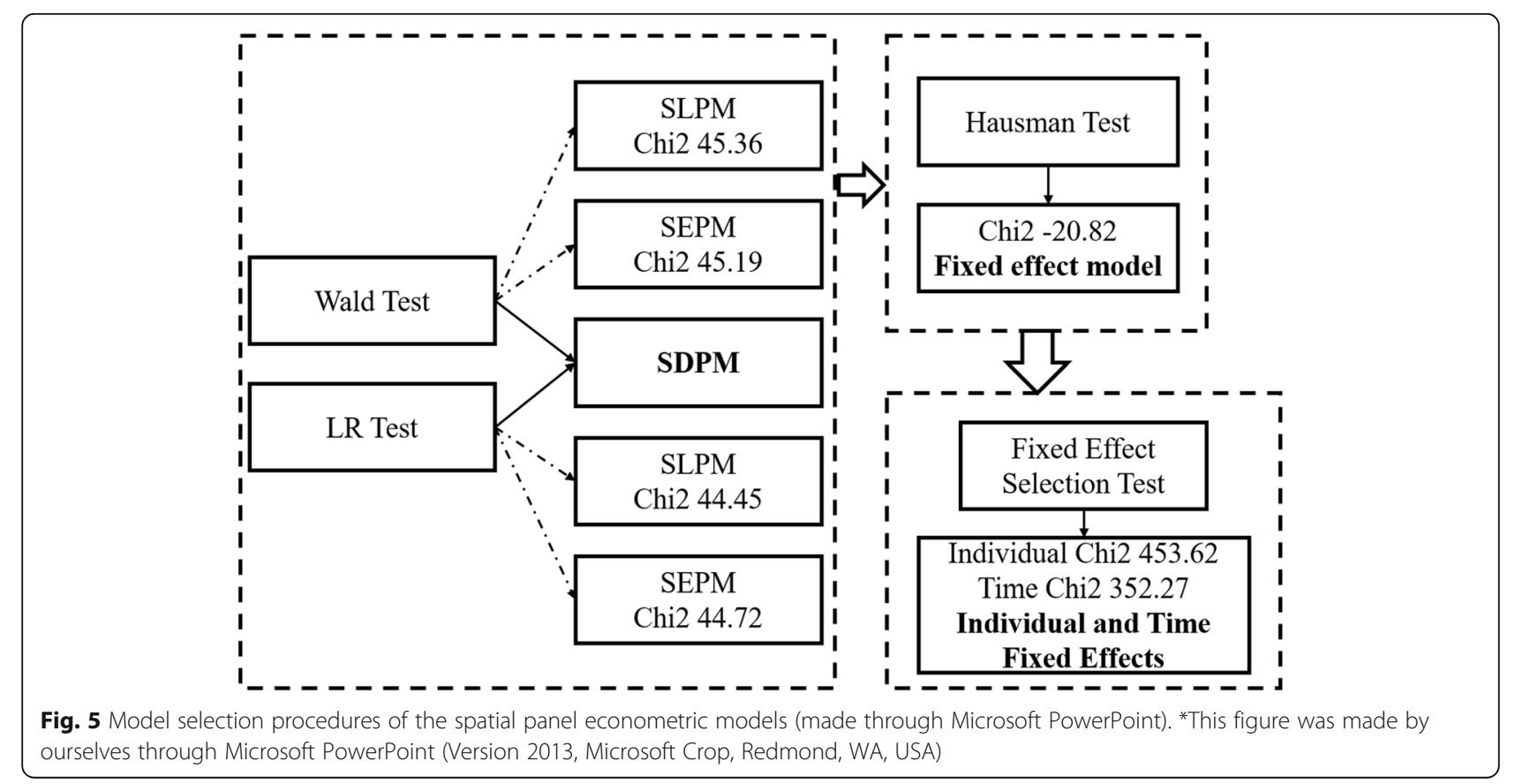


Table 7 Direct effects of independent variables on HFMD

\begin{tabular}{|c|c|c|c|c|c|c|}
\hline & $\begin{array}{l}\text { SDPM with individual } \\
\text { Fixed Effects }\end{array}$ & $\begin{array}{l}\text { SDPM with Time } \\
\text { Fixed Effects }\end{array}$ & $\begin{array}{l}\text { SDPM with individual } \\
\text { and Time Fixed Effects } \\
\text { (Best model) }\end{array}$ & $\begin{array}{l}\text { SDPM with } \\
\text { Random } \\
\text { Effects }\end{array}$ & $\begin{array}{l}\text { SEPM with individual } \\
\text { and Time Fixed } \\
\text { Effects }\end{array}$ & $\begin{array}{l}\text { SLPM with individual } \\
\text { and Time Fixed } \\
\text { Effects }\end{array}$ \\
\hline $\begin{array}{l}\text { Ln } \\
\text { (waterfall) }\end{array}$ & $0.106^{* * *}(3.61)$ & $0.133^{* * *}(4.14)$ & $0.071 * *(2.43)$ & $0.109 * * *(3.65)$ & - & $0.0493(1.67)$ \\
\hline temperature & $0.040(0.98)$ & $0.006(0.41)$ & $0.066(1.69)$ & $0.028(0.80)$ & - & $0.215^{* * *}(6.98)$ \\
\hline humidity & $0.005(0.58)$ & $-0.021^{* * *}(-3.95)$ & $0.004(0.43)$ & $0.002(0.21)$ & - & $0.021 * * *(2.96)$ \\
\hline
\end{tabular}

Note: Standard error in parentheses, ${ }^{* * *} p<0.01,{ }^{* *} p<0.05,{ }^{*} p<0.1$

The humidity, temperature and rainfall were relatively low in contrast with other regions in Shaanxi. Considering the HL cluster, there were several interesting characteristics. On one hand, high and low clusters could be witnessed at the same time within specific municipal cities. The core area would be normally surrounded by low clusters. In general, different clusters could be detected inside and outside municipal cities due to different socio-economic or meteorological factors. On the other hand, some border areas of the province showed high clusters compared with the surrounding region, such as Dingbian. The county is located in the junction of four provinces: Shaanxi, Gansu, Ningxia and Neimenggu. Thus, the region was easily effected by the policy, economic or meteorological factors of the adjacent provinces. LH clusters were mainly found in surrounding areas of high cluster regions. In addition, some southern regions in Shaanxi displayed low clusters in comparison with the central region. The southern region is characterized by low latitude, which means abundant precipitation, with a humid climate and high temperature.

Regarding the meteorological factors analysed in this study, rainfall, temperature and humidity were positively associated with the incidence rate of HFMD in specific regions. Du [44], Zheng [45], Wu [46], and Zhang [47] reported the same results in some high-risk areas such as Huanan, Hainan and Guangdong. In this study, we found a relationship between the meteorological factors of surrounding regions and the incidence rate of one specific region. The rainfall, temperature and humidity of surrounding regions were also positively associated with the incidence rate of HFMD of local counties. Naturally, the adjacent region normally experiencing same meteorological situation.
The strengths of this study are as follows: this study analysed the temporal and spatial analysis of HFMD in Shaanxi, China, and was the first study to analyse the situation of Shaanxi in the context of other counties, and the influence on HFMD from meteorological factors in the surrounding regions were explored for the first time. Moreover, the visualization of diseases at the county level provides a systematic and comprehensive method to understand the changing patterns of HFMD in Shaanxi. However, there were also some limitations in this study. In China, the meteorological data are obtained from monitoring points that are distributed in different regions. Thus, the meteorological data were not very precise. Furthermore, other determinants should be incorporated in future research.

\section{Conclusion}

In conclusion, this study aimed to analyse HFMD outbreaks and their spatial-temporal patterns in Shaanxi province, China. The incidence rate of HFMD displayed no trend from a temporal perspective. A high incidence rate of HFMD was observed from June to September, a season characterized by heavy rain, high temperature, and high humidity. The high-incidence spots were mainly located in rich regions.

Based on the findings in our study, spatial-temporal analysis and its tools proved to be effective research method for analysing the outbreak of HFMD, especially for local governments. The results could be applied by governments and the general public to take effective measures to prevent disease. From the government perspective, the region-targeted policies could be enacted and implemented in the future according to specific situations of different areas and their meteorological determinants. At the same time, meteorological conditions

Table 8 Spillover effects of independent variables on HFMD

\begin{tabular}{|c|c|c|c|c|c|c|}
\hline & $\begin{array}{l}\text { SDPM with } \\
\text { individual Fixed } \\
\text { Effects }\end{array}$ & $\begin{array}{l}\text { SDPM with } \\
\text { Time Fixed } \\
\text { Effects }\end{array}$ & $\begin{array}{l}\text { SDPM with individual } \\
\text { and Time Fixed Effects } \\
\text { (Best model) }\end{array}$ & $\begin{array}{l}\text { SDPM with } \\
\text { Random } \\
\text { Effects }\end{array}$ & $\begin{array}{l}\text { SEPM with individual } \\
\text { and Time Fixed } \\
\text { Effects }\end{array}$ & $\begin{array}{l}\text { SLPM with individual } \\
\text { and Time Fixed Effects }\end{array}$ \\
\hline Ln (waterfall) & $0.094(1.86)$ & $0.207^{* * *}(3.00)$ & $0.218^{* * *}(4.72)$ & $0.098^{*}(2.02)$ & - & $0.002(0.98)$ \\
\hline temperature & $0.082 *(2.01)$ & $0.182^{* * *}(8.15)$ & $0.450^{* * *}(6.19)$ & $0.094^{* *}(0.013)$ & - & $0.010(1.34)$ \\
\hline humidity & $0.003(0.25)$ & $0.078^{* * *}(6.41)$ & $0.045^{* * *}(3.25)$ & $0.000(0.02)$ & - & $0.001(1.18)$ \\
\hline
\end{tabular}

Note: Standard error in parentheses, ${ }^{* * *} p<0.01,{ }^{* *} p<0.05,{ }^{*} p<0.1$ 
normally extend to wide-ranging regions; thus, cooperation between surrounding regions is necessary. Furthermore, the local governments need take responsibility for the health management of immigrants and mobile populations. From the research institution perspective, spatial-temporal analysis should applied in the research of HFMD in central and local regions. From the citizen perspective, lifestyle could influence the control and prevention of HFMD; thus, citizens should cultivate good living habits, such as hand-washing and sanitary eating habits. In addition, citizens need to improve their awareness and knowledge of disease prevention.

\section{Supplementary Information}

The online version contains supplementary material available at https://doi. org/10.1186/s12889-021-10385-9.

Additional file 1.

Additional file 2.

Additional file 3.

\section{Abbreviations}

HFMD: Hand-foot-mouth disease; WHO: World Health Organization; EV71: Enterovirus 71; CDC: Chinese Center for Disease Control and Prevention; BTT: Beijing-Tianjin-Tangshan; GAM: General additive model; SXCDC: Shaanxi Provincial Center for Disease Control and Prevention; CMDC: China Meteorological Data Service Center; CMA: China Meteorological Administration; HH: High-high; HL: High-low; LH: Low-high; LL: Low-low; SLPM: Spatial Lag Panel Model; SEPM: Spatial Error Panel Model; SDPM: Spatial Durbin Panel Model; USA: The United States; WA: Washington; IL: Illinois; TX: Texas; CA: California; LISA: Local indicators of spatial association; ESRI: Environmental Systems Research Institute; Obs: Observations; Std. Dev.: Standard deviation; Min.: Minimum; Max: Maximum; IN: Incidence rate; LLR: Log Likelihood Ratio

\section{Acknowledgements}

The authors would like to thank the National Social Science Fund of China for its support and Shaanxi Provincial Centre of Disease Control and Prevention for sharing the valuable data.

\section{Authors' contributions}

LD, FL and YM conceptualized and designed the study. NZ put forward the outline of the article with JLL. BZ, XW made data analysis, draw pictures and drafted the manuscript. NZ and LD revised the article. All authors read and approved the final manuscript.

\section{Funding}

The study was funded by the Major Project of National Social Science Fund of China: Research on big health putting prevention first and construction of healthy China (grant number 17ZDA079). The funder had no role in the study design, data collection and analysis, interpretation of data, and writing the manuscript.

\section{Availability of data and materials}

The datasets of incidence rate of HFMD that support the findings of this study are available from Shaanxi Provincial Centre of Disease Control and Prevention but restrictions apply to the availability of these data, which were used under license for the current study, and so are not publicly available. Data are however available from the authors upon reasonable request and with permission of Shaanxi Provincial Centre of Disease Control and Prevention. The meteorological data generated or analyzed during this study are included in this published article (Appendix 1).

\section{Ethics approval and consent to participate}

This study used the secondary data from Shaanxi Provincial Center for Disease Control and Prevention and was thus exempted by the IRB of Xi'an Jiaotong University.

\section{Consent for publication}

Not applicable

\section{Competing interests}

The authors declare that they have no competing interests.

\section{Author details}

${ }^{1}$ School of Humanities and Social Science, Xi'an Jiaotong University, Xi'an, China. ${ }^{2}$ Health Commission of Xi'an, Xi'an, China. ${ }^{3}$ School of Public Policy and Administration, Xi'an Jiaotong University, Xi'an, China. ${ }^{4}$ Research Center for the Belt and Road Health Policy and Health Technology Assessment, Xi'an Jiaotong University, Xi'an, China. ${ }^{5}$ Department of Public Policy, City University of Hong Kong, Hong Kong, China. ${ }^{6}$ Water H. Shorenstein Asia-Pacific Research Center, Stanford University, Stanford, CA, USA. ${ }^{7}$ The Second Affiliated Hospital of Xi'an Jiaotong University, Xi'an, China. ${ }^{8}$ Shaanxi Provincial Centre of Disease Control and Prevention, Xi'an, China.

Received: 27 March 2020 Accepted: 3 February 2021

Published online: 17 February 2021

\section{References}

1. Ślebioda Z, Dorocka-Bobkowska B. Hand, foot and mouth disease as an emerging public health problem: case report of familial child-to-adult transmission. Dent Med Probl. 2018;55(1):99-104.

2. Zeng XW, Bloom MS, Dharmage SC, Lodge CJ, Chen D, Li S, Guo Y, Roponen M, Jalava P, Hirvonen MR. Prenatal exposure to perfluoroalkyl substances is associated with lower hand, foot and mouth disease viruses antibody response in infancy: findings from the Guangzhou birth cohort study. Sci Total Environ. 2019;663:60-7.

3. Xing W, Liao Q, Viboud C, Zhang J, Sun J, Wu JT, Chang Z, Liu F, Fang VJ, Zheng Y. Hand, foot, and mouth disease in China, 2008-12: an epidemiological study. Lancet Infect Dis. 2014;14(4):308-18.

4. Zhu F, Xu W, Xia J, Liang Z, Liu Y, Zhang X, Tan X, Wang L, Mao Q, Wu J. Efficacy, safety, and immunogenicity of an enterovirus 71 vaccine in China. N Engl J Med. 2014;370(9):818-28.

5. Shimizu H, Nakashima K. Surveillance of hand, foot, and mouth disease for a vaccine. Lancet Infect Dis. 2014;14:262.

6. World Health Organization. A Guide to Clinical Management and Public Health Response for Hand, Foot and Mouth Disease (HFMD). Geneva: WHO Press; 2011.

7. Mathes EF, Oza V, Frieden IJ, Cordoro KM, Yagi S, Howard R, Kristal L, Ginocchio CC, Schaffer J, Maguiness S. Eczema coxsackium and unusual cutaneous findings in an enterovirus outbreak. Pediatrics. 2013;132(1): e149-57.

8. Cabrerizo M, Tarragó D, Muñoz-Almagro C, del Amo E, Domínguez-Gil M, Eiros JMS, López-Miragaya I, Pérez C, Reina J, Otero A. Molecular epidemiology of enterovirus 71, coxsackievirus A16 and A6 associated with hand, foot and mouth disease in Spain. Clin Microbiol Infect. 2014;20(3): 0150-6.

9. Sousa IP, Burlandy FM, Tavares FN, da Silva EE. Enterovirus B74 associated with hand, foot and mouth disease. Infect Genet Evol. 2018;65:15-7.

10. Österback R, Vuorinen T, Linna M, Susi P, Hyypiä T, Waris M. Coxsackievirus A6 and hand, foot, and mouth disease, Finland. Emerg Infect Dis. 2009;15(9): 1485-8.

11. Onozuka D, Hashizume M. The influence of temperature and humidity on the incidence of hand, foot, and mouth disease in Japan. Sci Total Environ. 2011:410-411:119-25.

12. Puenpa J, Chieochansin T, Linsuwanon P, Korkong S, Thongkomplew S, Vichaiwattana P, Theamboonlers A, Poovorawan Y. Hand, foot, and mouth disease caused by Coxsackievirus A6, Thailand, 2012. Emerg Infect Dis. 2013; 19(4):641-3.

13. Chan KP, Goh KT, Chong CY, Teo ES, Lau G, Ling AE. Epidemic hand, foot and mouth disease caused by human enterovirus 71 , Singapore. Emerg Infect Dis. 2003;9(1):78-85.

14. Yi EJ, Shin YJ, Kim JH, Kim TG, Chang SY. Enterovirus 71 infection and vaccines. Clin Exp Vaccine Res. 2017;6(1):4-14. 
15. Wang Q, Wang Z. Epidemiology of hand foot and mouth disease in China, 2008. Dis Surveill. 2010;25:181-4.

16. Ni Z, Ling Q, Huilian Y, Xuelei Z, Pengfei Y. Spatial distribution of hand, foot and mouth disease and influence factors in Shaanxi province, 2015. Dis Surveill. 2017;32:818-23.

17. Sa C, Bing Z, Yan L, Yi Z, Shaoqi N. Dynamics and Epidemiological Characteristics of Hand, foot and month Disease in Shaanxi Province, 20092018. Chinese J Epidemiol. 2019;40:1120-4.

18. Mao Y, Zhang N, Zhu B, Liu J, He R. A descriptive analysis of the Spatiotemporal distribution of intestinal infectious diseases in China. BMC Infect Dis. 2019;19:766

19. Hassel C, Mirand A, Lukashev A, Terletskaia Ladwig E, Farkas A, Schuffenecker I, Diedrich S, Huemer HP, Archimbaud C, PeigueLafeuille $\mathrm{H}$. Transmission patterns of human enterovirus 71 to, from and among European countries, 2003 to 2013. Eurosurveillance. 2015; 20(34):30005

20. Bian L, Wang Y, Yao X, Mao Q, Xu M, Liang Z. Coxsackievirus A6: a new emerging pathogen causing hand, foot and mouth disease outbreaks worldwide. Expert Rev Anti Infect Ther. 2015;13(9):1061-71.

21. Lee CCD, Tang JH, Hwang JS, Shigematsu M, Chan TC. Effect of meteorological and geographical factors on the epidemics of hand, foot, and mouth disease in island-type territory, East Asia. Biomed Res Int. 2015; 2015:805039.

22. Koh WM, Bogich T, Siegel K, Jin J, Chong EY, Tan CY, Chen MIC, Horby $P$, Cook AR. The epidemiology of hand, foot and mouth disease in Asia: a systematic review and analysis. Pediatr Infect Dis J. 2016;35(10):e285300.

23. Smith, S.W. Moving Average Filters. Digital Signal Processing; 2003 ISBN 0966017633.

24. Tobler W. On the first law of geography: a reply. Ann Assoc Am Geogr. 2004;94(2):304-10.

25. Goodchild MF. Geographical information science. Int J Geogr Inf Syst. 1992; 6(1):31-45.

26. Anselin L. Local indicators of spatial association-LISA. Geogr Anal. 1995; 27(2):93-115.

27. Elhorst, J.P. Spatial Panel Data Models. Handbook of Applied Spatial Analysis; 2010.

28. Elhorst JP. Specification and estimation of spatial panel data models. Int Reg Sci Rev. 2003;26(3):244-68

29. Anselin L. Spatial externalities, spatial multipliers, and spatial econometrics. Int Reg Sci Rev. 2003;26(2):153-66.

30. Elhorst, J.P. Spatial econometrics: from cross sectional data to spatial panels; 2010; ISBN 978-1-4200-7287-7.

31. Paul Elhorst, J. Spatial panel models. Handbook of Regional Science; 2014 ISBN 9783642234309.

32. Anselin, L.; Bera, A.K. Spatial dependence in linear regression models with an introduction to spatial econometrics. Handbook of Applied Economic Statistics; 1998.

33. Lei $F$, Kewei $L$, Ling $X$, Jianwei $L$. The Spatialtemporal Characteristics and Influencing Factors of Floating Population in Shaanxi Province. J. Shaanxi Norm Univ Nature Sci Ed. 2015:43:92-8.

34. Li Y, Zhang J, Zhang X. Modeling and preventive measures of hand, foot and mouth disease (HFMD) in China. Int J Environ Res Public Health. 2014; 11(3):3108-17.

35. Liu L, Zhao X, Yin F, Lv Q. Spatio-temporal clustering of hand, foot and mouth disease at the county level in Sichuan province, China, 2008-2013. Epidemiol Infect. 2015;143(4):831-8

36. Liu Y, Wang X, Liu Y, Sun D, Ding S, Zhang B, Du Z, Xue F. Detecting spatialtemporal clusters of HFMD from 2007 to 2011 in Shandong Province, China. PLoS One. 2013;8(5):e63447.

37. Xie YH, Chongsuvivatwong V, Tang Z, McNeil EB, Tan Y. Spatio-temporal clustering of hand, foot, and mouth disease at the county level in Guangxi, China. PLoS One. 2014;9(2):e88065.

38. Deng T, Huang Y, Yu S, Gu J, Huang C, Xiao G, Hao Y. Spatial-Temporal Clusters and Risk Factors of Hand, Foot, and Mouth Disease at the District Level in Guangdong Province, China. PLoS One. 2013;8(2): e56943.

39. Gui J, Liu Z, Zhang T, Hua Q, Jiang Z, Chen B, Gu H, Lv H, Dong C. Epidemiological characteristics and spatial-temporal clusters of hand, foot, and mouth disease in Zhejiang Province, China, 2008-2012. PLoS One. 2015; 10(9):e0139109.
40. Yang $L, Y e M, H e B J$. CFD simulation research on residential indoor air quality. Sci Total Environ. 2014;472:1137-44.

41. Samphutthanon R, Tripathi NK, Ninsawat S, Duboz R. Spatio-temporal distribution and hotspots of hand, foot and mouth disease (HFMD) in northern Thailand. Int J Environ Res Public Health. 2013;11(1):312-36.

42. Nguyen HX, Chu C, Nguyen HLT, Nguyen HT, Do CM, Rutherford S, Phung D. Temporal and spatial analysis of hand, foot, and mouth disease in relation to climate factors: a study in the Mekong Delta region, Vietnam. Sci Total Environ. 2017:581-582:766-72.

43. Sham NM, Krishnarajah I, Ibrahim NA, Lye MS. Temporal and spatial mapping of hand, foot and mouth disease in Sarawak, Malaysia. Geospat Health. 2014;8(2):503-7.

44. Du Z, Zhang W, Zhang D, Yu S, Hao Y. The threshold effects of meteorological factors on Hand, foot, and mouth disease (HFMD) in China, 2011. Sci Rep. 2016;6:36351.

45. Zheng S, Cao CX, Cheng JQ, Wu YS, Xie X, Xu M. Epidemiological features of hand-foot-and-mouth disease in Shenzhen, China from 2008 to 2010. Epidemiol Infect. 2014;142(8):1751-62.

46. Wu X, Hu S, Kwaku AB, Li Q, Luo K, Zhou Y, Tan H. Spatio-temporal clustering analysis and its determinants of hand, foot and mouth disease in Hunan, China, 2009-2015. BMC Infect Dis. 2017;17(1):645.

47. Suling Z, Xiaofeng W. Epidemiological characteristics, etiological pathogen and meteorological factors analysis of hand, foot and mouth disease (HFMD) in Western Hainan Province, China, 2010-2016. Biomed Res. 2017; 28(12):5479-83.

\section{Publisher's Note}

Springer Nature remains neutral with regard to jurisdictional claims in published maps and institutional affiliations.
Ready to submit your research? Choose BMC and benefit from:

- fast, convenient online submission

- thorough peer review by experienced researchers in your field

- rapid publication on acceptance

- support for research data, including large and complex data types

- gold Open Access which fosters wider collaboration and increased citations

- maximum visibility for your research: over $100 \mathrm{M}$ website views per year

At $\mathrm{BMC}$, research is always in progress.

Learn more biomedcentral.com/submissions 